\title{
PHAGOCYTOSIS OF SPERMATOZOA BY LEUCOCYTES IN BOVINE CERVICAL MUCUS IN VITRO
}

\author{
P. E. MATTNER* \\ Physiology Department, National Institute for Research in Dairying, \\ Shinfield, Reading, Berks.
}

(Received 27th January 1969)

Leucocytes containing ingested spermatozoa have been found in the female genital tract in small laboratory animals (McDonald, Black, McNutt \& Gasida, 1952; Austin, 1957; Yanagimachi \& Chang, 1963), in pigs (Pitkjanen, 1960) and in ruminants (Howe \& Black, 1963; Mattner, 1968). Using electron microscopy, Bedford (1965) found that the cell membranes and acrosomal cap remained intact in many of the spermatozoa present within leucocytes obtained from the uteri of oestrous rabbits inseminated $12 \mathrm{hr}$ previously. The latter finding indicates that leucocytes may ingest undamaged, living spermatozoa as well as dead or damaged spermatozoa in the female genital tract. The present communication reports visual observations on the ingestion of motile spermatozoa in bovine cervical mucus and the failure of leucocytes to attack dead spermatozoa in the same medium.

Gervical mucus containing numerous polymorphonuclear leucocytes was obtained from cows in late oestrus. Threads of mucus and bovine semen were placed in contact on slides, covered with coverslips and incubated at $37^{\circ} \mathrm{C}$ on the stage of a phase-contrast microscope. Spermatozoa swam through the mucus and occasionally collided with the contained leucocytes. In many instances the leucocytes adhered to and subsequently engulfed the spermatozoa that impinged upon them.

This was effected by the projection of a pseudopodium-like process from the leucocyte that spread over the sperm head and completely enveloped it in 5 to 10 min. Generally, the 'pseudopodium' also enveloped the midpiece and part of the tail of the spermatozoon and then regained an ovoid or almost spherical shape within $1 \frac{1}{2}$ to $2 \mathrm{hr}$. The spermatozoa attacked by the leucocytes appeared to be normal cells before they were engulfed. During the initial stages of their being engulfed, they continued to swim vigorously through the mucus. However, their flagellation usually decreased markedly once the head had been completely enveloped and ceased several minutes afterwards.

Semen that had previously been frozen to kill all the spermatozoa, was then gently stirred into fresh samples of mucus which were spread on slides and incubated as described previously. In each of three such preparations, the positions of twelve to fifteen leucocytes lying within 2 to $5 \mu$ of spermatozoa were fixed relative to points on a grid within an eyepiece of the microscope.

* Present address: CSIRO, Division of Animal Physiology, Ian Clunies Ross Animal Research Laboratory, Prospect, N.S.W., Australia. 
During an observation period of $1 \mathrm{hr}$, none of these leucocytes migrated toward the nearby spermatozoa; all remained stationary in the mucus. The other leucocytes in the preparations were also examined but none contained spermatozoa.

Subsequently, the relative ability of leucocytes to attack living or dead spermatozoa in liquefied mucus was tested. Leucocytes were obtained from bovine blood by a modification of the method described by Agostini \& Ideo (1965) for harvesting lymphocytes from human blood. The mucus was liquefied by maceration in a mechanical blender. Ten pairs of suspensions, each containing $4 \times 10^{6}$ leucocytes and $1 \times 10^{8}$ spermatozoa in $4 \mathrm{ml}$ of liquefied mucus, were incubated at $37^{\circ} \mathrm{C}$ for $1 \frac{1}{2} \mathrm{hr}$ under aerobic conditions while being shaken continuously in Warburg flasks. In one of each pair of suspensions, over $70 \%$ of the spermatozoa were motile initially (live spermatozoa preparations); the spermatozoa in the other suspension had previously been killed by cold shock (dead spermatozoa preparations). The phagocytic activity was assessed by mixing samples of the suspensions $1: 4$ with $10 \%$ formol saline and examining 200 leucocytes from each suspension by phase-contrast microscopy. In the preparations of live spermatozoa, 46.0 (S.E. 3) $\%$ of the leucocytes contained at least one spermatozoan head. The corresponding proportion was 42.6 (S.E. 3) \% for the preparations of dead spermatozoa.

Consequently, it appears that factors associated with the physical structure of unliquefied cervical mucus were responsible for the leucocytes failing to attack dead spermatozoa in that material, evidently by preventing migration of the leucocytes. As cervical mucus is a gel it would probably offer little resistance to amoeboid progression of leucocytes through its substance, but it is possible that 'exudates' from spermatozoa may not readily diffuse through unliquefied mucus and may, accordingly, fail to stimulate leucotaxis. However, the present results indicate that because of their intrinsic motility, live spermatozoa are more likely than are dead spermatozoa to be engulfed by leucocytes present in the vaginal and cervical mucus, simply because of a greater probability of contact with the leucocytes.

This work formed part of a programme of research on cervical mucus supported by the Population Council Inc., The Rockefeller University, New York.

\section{REFERENCES}

Agostini, A. \& Ideo, G. (1965) Separation of large numbers of lymphocytes from human blood. Experientia, 21, 82.

Austin, G. R. (1957) Fate of spermatozoa in the uterus of the mouse and rat. F. Endocr. 14, 335.

BEDFord, J. M. (1965) Effect of environment on phagocytosis of rabbit spermatozoa. F. Reprod. Fert. 9, 249.

Howe, G. R. \& BLACK, D. L. (1963) Spermatozoan transport and leucocytic responses in the reproductive tract of calves. F. Reprod. Fert. 6, 305.

McDonald, L. E., Black, W. G., McNutT, S. H. \& CAsida, L. E. (1952) The response of the rabbit uterus to instillation of semen at different phases of the oestrous cycle. Am. F. vet. Res. 13, 419.

Mattner, P. E. (1968) The distribution of spermatozoa and leucocytes in the female genital tract in goats and cattle. J. Reprod. Fert. 17, 253.

Pitkjanen, I. G. (1960) The fate of spermatozoa in the uterus of the sow. Zh. obshch. Biol. 21, 28 (Anim. Breed. Abstr. 28, 299, 1960).

Yanagimachi, R. \& Chang, M. C. (1963) Infiltration of leucocytes into the uterine lumen of the golden hamster during the oestrous cycle and following mating. F. Reprod. Fert. 5, 389. 